\title{
The Frequency of Taurodontism in the Turkish Population
}

\author{
H. Sinan Topcuoglu ${ }^{1}$, Ertuğrul Karataş ${ }^{1}$, Hakan Arslan ${ }^{1}$, Mustafa Koseoglu ${ }^{2}$, M.Sinan Evcil ${ }^{2}$ \\ ${ }^{1}$ DDS. Department of Restorative Dentistry and Endodontics, Faculty of Dentistry, Ataturk University, Erzurum, Turkey. \\ ${ }^{2}$ DDS, PhD. Department of Restorative Dentistry and Endodontics, Faculty of Dentistry, Ataturk University, Erzurum, Turkey.
}

Correspondence

Department of Restorative Dentistry and Endodontics,

Faculty of Dentistry,

Ataturk University,

Erzurum, 25240, TURKEY

E-mail address:dtertu@windowslive.com

Topcuoglu HS, Karataş E, Arslan H, Koseoglu M, Evcil MS. The Frequency of Taurodontism in the Turkish Population. J Clin Exp Dent. 2011;3(4):e284-8.

http://www.medicinaoral.com/odo/volumenes/v3i4/jcedv3i4p284.pdf

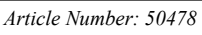

\begin{abstract}
Objectives: The aim of this study was to assess the prevalence and degree of taurodontism in a group of Turkish adult dental patients.

Study design: A retrospective study was performed using panoramic radiography of 490 patients ranging in age from 18 to 65 . These patients were analyzed for taurodontism. Descriptive characteristics of sex, jaws, and localization were recorded. The data was analyzed using the Pearson chi-square test.

Results: Taurodontism was detected in $22.8 \%$ of patients and $4.2 \%$ of the teeth examined. Anomalies were found in $22.2 \%$ of females compared with $23.8 \%$ of males. However, no significant difference was found between the genders $(\mathrm{p}>0.05)$. Taurodontism was more distributed in the maxilla than in the mandible. The maxillary third molar was the most commonly affected tooth.

Conclusion: According to these results, taurodontism is not uncommon in the Turkish population. However, further studies are required to assess its distribution in the general population.
\end{abstract}

Key Words: Prevalence, Taurodontism, Turkish. 


\section{Introduction}

Taurodontism is one of the most important abnormalities in tooth morphology. Teeth affected by this abnormality present with elongated pulp chambers and apical floor displacement from bifurcation or trifurcation of the roots. It may be unilateral or bilateral and affect both permanent and primary teeth (1). The etiology of taurodontism is unclear. However, Hamner et al.(2) indicated that taurodontism is caused by the failure of Hertwig's epithelial sheath diaphragm to invaginate at the proper horizontal level. In addition, some reports suggest that it may be associated with alterations in the sex chromosomes, such as Down's syndrome, Khnefelter's syndrome, or Trico-dento-osseous syndrome and certain diseases such as hypophosphatasia (3-5).

The first quantitative study of taurodontism was conducted by Shaw in 1928. The researcher classified taurodont teeth into hypo-, meso-, and hypertaurodont forms. This classification has been made based on the relative displacement of the pulp floor (1). Eventually, some researchers evaluated taurodontism using anatomical points on radiographs (6-9). In recent years, Shifman and Chanannel's index has been the most widely used system $(10,11)$. They proposed that taurodontism was present when the distance from the lowest point at the occlusal end of the pulp chamber (point A) to the highest point of at the apical end of the chamber (point $\mathrm{B})$ divided by the distance from A to the apex is 0.2 or greater $(x / y \geq 0.2)$ and when the distance from $B$ to the cementoenamel junction (CEJ) is greater than $2.5 \mathrm{~mm}$ (z>2.5mm) (Fig 1).

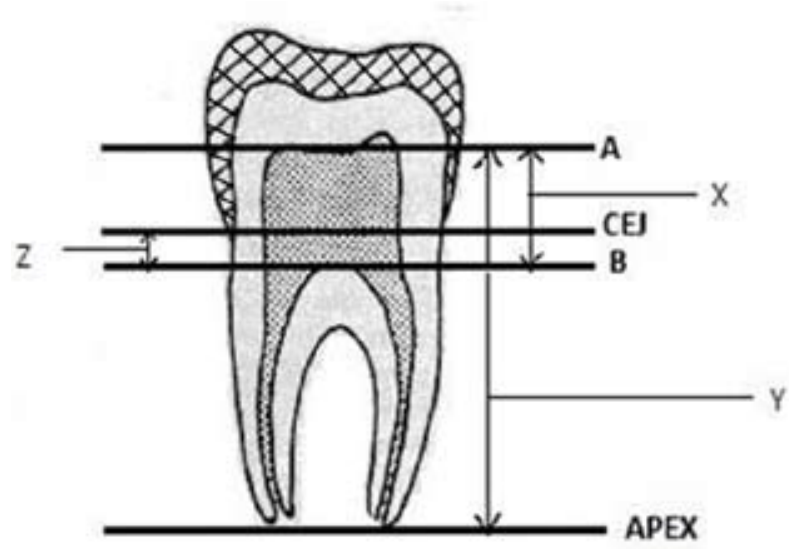

Fig. 1. The measurements, based on study by Shifman and Chanannel were used to determine presence of taurodontism. Point A: the lowest point at the occlusal end of the pulp chamber. Point B: the highest point at the apical end of the pulp chamber. CEJ: the cementoenamel junction

A taurodont tooth shows wide variation in the size and shape of the chamber with varying degrees of obliteration and canal configuration, apically positioned canal orifices, and the potential for additional root canal sys- tems. Thus, endodontic treatment of taurodontic teeth becomes a challenge for clinicians $(10,12)$.

The purpose of this investigation was to evaluate the prevalence and degree of taurodontism in a group of Turkish adult dental patients.

\section{Material and Methods}

A total of 713 patients' records at the Department of Endodontics at Ataturk University were reviewed. Only the records that had adequate radiographic surveys showing the teeth properly were chosen for inclusion in the study; panoramic radiographs were used. In addition, teeth with carious, restored, and immature tooth or root resorption were not included in the study. A total of 223 dental records were excluded, resulting in a final sample size of 490. Records of patients ranging in age from 18 to 65 were included in this study.

All radiographs were classified subjectively with respect to the presence or absence of taurodontism. Any questionable finding was included in the positive group at this stage. All positive radiographs were subsequently reviewed by both investigators together, and radiographs were objectively evaluated with calipers using the criteria of Shifman and Chanannel for taurodontism. The reviewed radiographs were evaluated again by the same investigators one week later so that the differences between investigators could be determined. Different results were not obtained following the second evaluation. Statistical analysis of the data was performed using the SPSS computer program (SPSS 16.0 NY,USA), and the frequency distribution for taurodontism was calculated. The Pearson chi-square test was used to compare the frequency of taurodontism between male and female patients $(\mathrm{p}<0.05)$.

\section{Results}

We examined 7684 teeth of 490 patients and detected $322(4.2 \%)$ taurodont teeth in $112(22.8 \%)$ patients. Among the 490 patients, taurodontism was more distributed in the maxilla $(6.5 \%, \mathrm{n}=252)$ than in the mandible $(2 \%, n=77)$. Also, 104 of the 112 taurodontism patients had at least one taurodont tooth in the maxilla (92.9\%), and 37 of them had a taurodont tooth in the mandible $(33 \%)$. The number of patients who had taurodontism in both the maxilla and the mandible was $29(25.9 \%)$. In taurodontic patients, there was a statistically significant difference between the jaws $(\mathrm{p}=0.000)$.

The most frequently taurodont teeth were found to be the maxillary third molars $(17.1 \%)$, followed by the maxillary second molars $(12.7 \%)$ in male patients; in female patients, taurodont teeth were most frequently found to be the maxillary second molars (13.6\%), followed by the maxillary third molars (11.6\%). There was no taurodont mandibular premolar tooth in a patient of either gender. Additionally, regardless of gender, the maxillary premo- 
lars were the second least affected tooth group (Tables I, II, III, and IV). Anomalies were found in $22.2 \%$ ( $n=$ $66)$ of females compared with $23.8 \%(n=46)$ of males.
However, no significant difference was found between the genders $(p=0.675)$. Figure 2 shows example of multiple taurodontism on panoramic radiography.

\begin{tabular}{llllll}
\hline & $\mathbf{1}^{\text {st }} \mathbf{p r e m o l a r}$ & $\mathbf{2}^{\text {nd }} \mathbf{p r e m o l a r}$ & $\mathbf{1}^{\text {st }}$ molar & $\mathbf{2}^{\text {nd }}$ molar & $\mathbf{3}^{\text {rd }}$ molar \\
\hline Total examined teeth & 372 & 357 & 279 & 362 & 262 \\
\hline Hypotaurodontism & 0 & 0 & 2 & 8 & 9 \\
Mesotaurodontism & 0 & 0 & 1 & 5 & 3 \\
\hline Hypertaurodontism & 0 & 0 & 0 & 3 & 0 \\
Total taurodont teeth & 0 & 0 & 3 & 16 & 12 \\
Prevalence & $0 \%$ & $0 \%$ & $1 \%$ & $4.4 \%$ & $4.6 \%$ \\
\hline
\end{tabular}

Table 1. Prevalence of taurodontism in the mandible of male patients

\begin{tabular}{llllll}
\hline & $\mathbf{1}^{\text {st }}$ premolar & $\mathbf{2}^{\text {nd }}$ premolar & $\mathbf{1}^{\text {st }} \mathbf{m o l a r}$ & $\mathbf{2}^{\text {nd }}$ molar & $\mathbf{3}^{\text {rd }} \mathbf{m o l a r}$ \\
\hline Total examined teeth & 345 & 335 & 288 & 352 & 263 \\
\hline Hypotaurodontism & 2 & 2 & 10 & 24 & 23 \\
Mesotaurodontism & 1 & 0 & 9 & 17 & 19 \\
Hypertaurodontism & 0 & 0 & 3 & 4 & 3 \\
Total taurodont teeth & 3 & 2 & 22 & 45 & 45 \\
\hline Prevalence & $0.9 \%$ & $0.6 \%$ & $7.6 \%$ & $12.7 \%$ & $17.1 \%$ \\
\hline
\end{tabular}

Table 2. Prevalence of taurodontism in the maxilla of male patients

\begin{tabular}{llllll}
\hline & $\mathbf{1}^{\text {st }}$ premolar & $\mathbf{2}^{\text {nd }}$ premolar & $\mathbf{1}^{\text {st }} \mathbf{m o l a r}$ & $\mathbf{2}^{\text {nd }} \mathbf{m o l a r}$ & $\mathbf{3}^{\text {rd }} \mathbf{m o l a r}$ \\
\hline Total examined teeth & 519 & 511 & 351 & 455 & 366 \\
\hline Hypotaurodontism & 0 & 0 & 3 & 11 & 13 \\
Mesotaurodontism & 0 & 0 & 1 & 6 & 6 \\
\hline Hypertaurodontism & 0 & 0 & 0 & 3 & 3 \\
Total taurodont teeth & 0 & 0 & 4 & 20 & 22 \\
Prevalence & $0 \%$ & $0 \%$ & $1.1 \%$ & $4.4 \%$ & $6 \%$ \\
\hline
\end{tabular}

Table 3. Prevalence of taurodontism in the mandible of female patients

\begin{tabular}{llllll}
\hline & $\mathbf{1}^{\text {st }}$ premolar & $\mathbf{2}^{\text {nd }}$ premolar & $\mathbf{1}^{\text {st }}$ molar & $\mathbf{2}^{\text {nd }}$ molar & $\mathbf{3}^{\text {rd }} \mathbf{m o l a r}$ \\
\hline Total examined teeth & 522 & 496 & 422 & 491 & 336 \\
Hypotaurodontism & 1 & 5 & 9 & 28 & 18 \\
\hline Mesotaurodontism & 0 & 2 & 10 & 32 & 13 \\
Hypertaurodontism & 0 & 1 & 1 & 7 & 8 \\
Total taurodont teeth & 1 & 8 & 20 & 67 & 39 \\
Prevalence & $0.2 \%$ & $1.6 \%$ & $4.7 \%$ & $13.6 \%$ & $11.6 \%$ \\
\hline
\end{tabular}

Table 4. Prevalence of taurodontism in the maxilla of female patients 


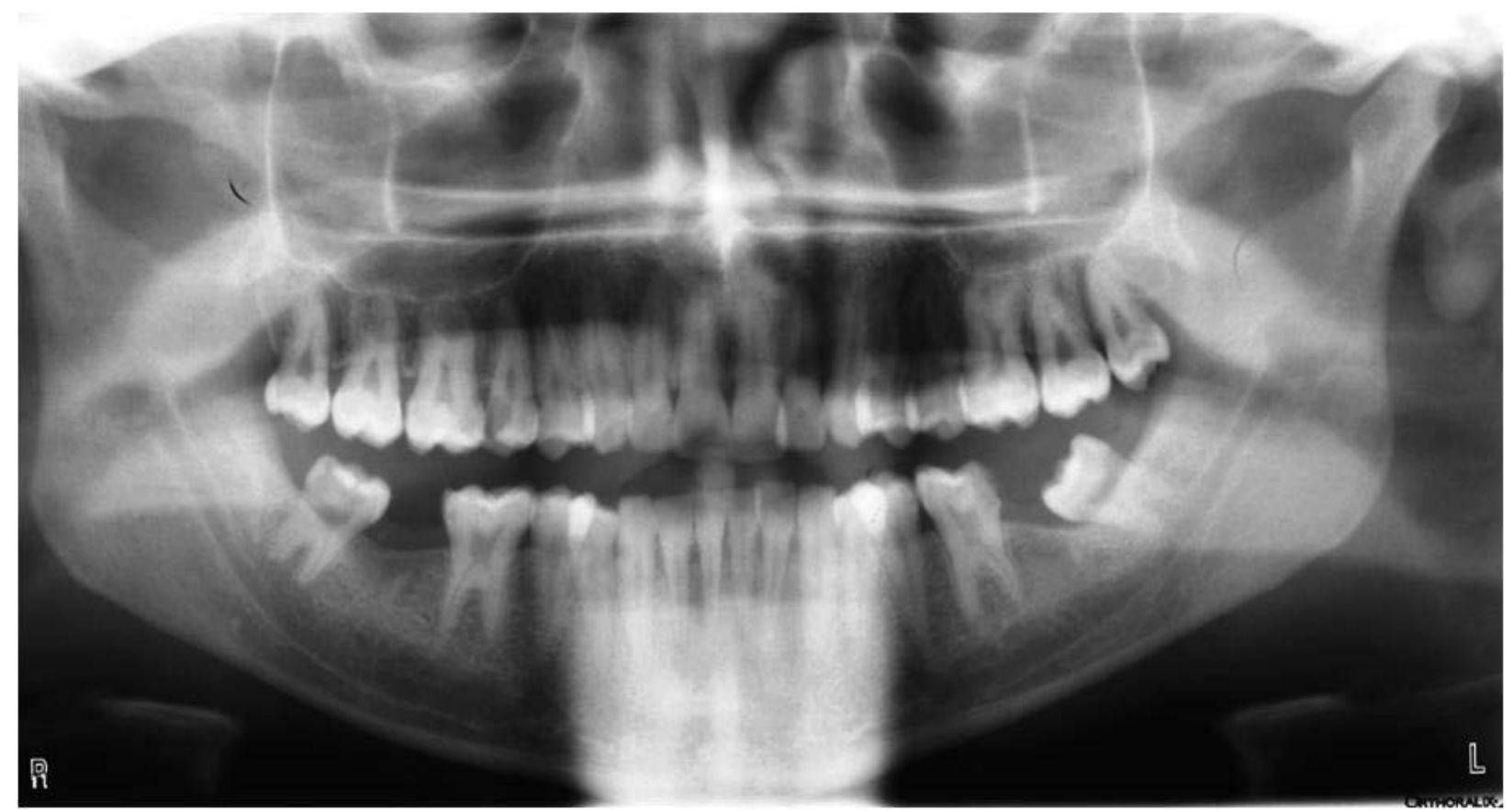

Fig. 2. Taurodontism in the upper and lower molars

\section{Discussion}

Taurodontism is a dental anomaly characterized by large pulp chambers and short roots (13). Although this anomaly is generally found in patients without any syndrome, several reports have been published in which taurodontism appears as a part of various syndromes, such as amelogenesis imperfects, Down's syndrome, tricho-dento-osseous syndrome, and Klinefelter syndrome (3, 4, 6, 14). Many of these disorders have oral manifestations, which can be detected on dental radiographs as alterations in the morphology or chemical composition of the teeth $(3,15,16)$. However, it is considered an anatomic difference that can occur in a normal population (8). In this study, we did not examine a relationship between syndromes and taurodontism.

Clinically, a taurodont seems to be a normal tooth. Therefore, a diagnosis of taurodontism is usually made from diagnostic radiographs (17). Periapical, bite-wing, lateral, or panoramic radiographs were used to determine the presence of taurodont teeth $(7,8)$. However, Tulensalo et al. (18) studied a method of evaluating taurodontism using panoramic radiographs by measuring the distance between the baseline and the highest point of the floor of the pulp chamber. In our study, we used panoramic radiographs, as in many previous reports (19-21).

Many researchers have tried to develop an objective method for assessment of taurodontism using radiography. Among these methods, Shifman and Chanannel's method is currently a widely used system $(10,11)$. That is why we used this method in the present study.

It is necessary to find all of the root canals in endodontic treatment to ensure satisfactory prognosis. However, endodontic treatment in taurodont teeth is complex and difficult because taurodontism presents a challenge during negotiation, instrumentation, and obturation in root canal treatment $(10,17)$. Increased hemorrhage during access opening may be mistaken for perforation. Since the roots are short and the pulpal floor is placed apically, care should be taken to prevent perforation (22). Also, if a taurodont tooth has an unusual root canal system in terms of shape and number, instrumentation of the root canal may become too difficult (23).

During root canal instrumentation, the canals can be instrumented with only the apical third of the file because of the short canals (especially in the hyper-taurodont type) (23). Some authors have performed the root canal instrumentation procedure with circumferential filling using $\mathrm{K}$-files, while others have performed it using the balanced-force technique $(10,14)$. In view of the complexity of the root canal anatomy and the proximity of the buccal orifices, completing the obturation procedure of the root canal system in taurodontism is difficult. Tsesis et al. suggested that a combination of the lateral compaction technique and the warm vertical compaction technique may be used to obturate a taurodont tooth (10). In another case, the authors performed root canal obturation using the roll-cone technique (14).

Taurodontism may affect molars and premolars; however, in the literature the most frequently affected teeth type varies. Several researchers have reported that the mandibular second molars are the most frequently affected $(1,6,8)$. Conversely, in our research, the most frequently affected teeth were the maxillary molars (in males) and the maxillary second molars (in females). 
Consistent with our results, the maxillary molars were found to be the most commonly affected teeth type in some studies $(20,21,24)$. In this study, we did not find taurodontic premolars in the mandible, which is consistent with previous reports (24).

According to our results, the prevalence of taurodontism in both jaws was $25.9 \%$. There are few case reports presenting taurodontism in both jaws (25-27). Additionally, many publications that were examined do not include the prevalence of taurodontism in both jaws. Also, 92.9\% of the patients with at least one taurodont tooth had one in the maxilla, while $33 \%$ had one in the mandible. The prevalence of taurodontism in the mandible (33\%) has almost same ratio as the prevalence of taurodontism in both jaws $(25.9 \%)$. These results mean that, if there is a taurodont tooth in the mandible, the possibility of a taurodont tooth being present in the maxilla has a high likelihood.

The results of this study demonstrated that the prevalence of taurodontism is $4.2 \%$, which is similar to the results of some previous reports $(7,8,24)$. However, in contrast to our results in the literature, many different prevalence ratios ranging from $0.25 \%$ to $48 \%$ have been reported $(20,21,28)$. The examined population, sample size, method used for interpretation of taurodontism, and type of teeth examined may be the causes of these differing results.

\section{Conclusion}

It can be concluded that, due to the relatively small sample size, the prevalence figures for taurodontism in our study should be considered with caution, as they may not be representative of the overall Turkish population. Nonetheless, the findings form a source for further studies. Additionally, clinicians should be aware of the presence of taurodont teeth because they are not uncommon.

\section{Acknowledgement}

The authors deny any financial affiliations related to this study or its sponsors.

\section{References}

1. Jafarzadeh H, Azarpazhooh A, Mayhall JT. Taurodontism: a review of the condition and endodontic treatment challenges. Int Endod J. 2008;41:375-88.

2. Hamner JE 3rd, Witkop CJ Jr, Metro PS. Taurodontism;report of a case. Oral Surg Oral Med Oral Pathol. 1964;18:409-18.

3. Islam M, Lurie AG, Reichenberger E. Clinical features of trichodento-osseous syndrome and presentation of three new cases: an addition to clinical heterogeneity. Oral Surg Oral Med Oral Pathol Oral Radiol Endod. 2005;100:736-42.

4. Yeh SC, Hsu TY. Endodontic treatment in taurodontism with Klinefelter's syndrome: a case report. Oral Surg Oral Med Oral Pathol Oral Radiol Endod. 1999;88:612-5.

5. Jaspers MT. Taurodontism in the Down syndrome. Oral Surg Oral Med Oral Pathol. 1981;51:632-6.

6. Blumberg JE, Hylander WL, Goepp RA. Taurodontism: a biometric study. Am J Phys Anthropol. 1971;34:243-55.

7. Jorgenson RJ, Salinas CF, Shapiro SD. The prevalence of tau- rodontism in a select population. J Craniofac Genet Dev Biol. 1982;2:125-35.

8. Shifman A, Chanannel I. Prevalence of taurodontism found in radiographic dental examination of 1,200 young adult Israeli patients. Community Dent Oral Epidemiol.1978;6:200-3.

9. Feichtinger C, Rossiwall B. Taurodontism in human sex chromosome aneuploidy. Arch Oral Biol. 1977;22:327-9.

10. Tsesis I, Shifman A, Kaufman AY. Taurodontism: an endodontic challenge. Report of a case. J Endod. 2003 May;29(5):353-5.

11. Chaparro Gonzalez NT, Leidenz Bermudez JS, Gonzalez Molina EM, Padilla Olmedillo JR. Multiple bilateral taurodontism. A case report. J Endod. 2010;36:1905-7.

12. Rao A, Arathi R. Taurodontism of deciduous and permanent molars: report of two cases. J Indian Soc Pedod Prev Dent. 2006;24:42-4.

13. Bharti R, Chandra A, Tikku AP, Wadhwani KK. Taurodontism, an endodontic challenge: a case report. J Oral Sci. 2009;51:471-4.

14. Prakash R, Vishnu C, Suma B, Velmurugan N, Kandaswamy D. Endodontic management of taurodontic teeth. Indian J Dent Res. 2005;16:177-81.

15. Bell J, Civil CR, Townsend GC, Brown RH. The prevalence of taurodontism in Down's syndrome. J Ment Defic Res. 1989;33:46776.

16. Schulman GS, Redford-Badwal D, Poole A, Mathieu G, Burleson J, Dauser D. Taurodontism and learning disabilities in patients with Klinefelter syndrome. Pediatr Dent. 2005;27:389-94.

17. Durr DP, Campos CA, Ayers CS. Clinical significance of taurodontism. J Am Dent Assoc. 1980;100:378-81.

18. Tulensalo T, Ranta R, Kataja M. Reliability in estimating taurodontism of permanent molars from orthopantomograms. Community Dent Oral Epidemiol. 1989; 17:258-62.

19. Schalk-van der Weide Y, Steen WH, Bosman F. Taurodontism and length of teeth in patients with oligodontia. J Oral Rehabil. 1993;20:401-12.

20. MacDonald-Jankowski DS, Li TT. Taurodontism in a young adult Chinese population. Dentomaxillofac Radiol. 1993;22:140-4.

21. Sarr M, Toure B, Kane AW, Fall F, Wone MM. Taurodontism and the pyramidal tooth at the level of the molar. Prevalence in the Senegalese population 15 to 19 years of age. Odontostomatol Trop. 2000;23:31-4.

22. Bhat SS, Sargod S, Mohammed SV. Taurodontism in deciduous molars - A case report. J Indian Soc Pedod Prev Dent. 2004;22:193-6.

23. Hayashi Y. Endodontic treatment in taurodontism. J Endod. 1994;20:357-8.

24. Darwazeh AM, Hamasha AA, Pillai K. Prevalence of taurodontism in Jordanian dental patients. Dentomaxillofac Radiol. 1998;27:163-5.

25. Fuks AB, Levin S, Grinbaum M, Chosack A. Multiple taurodontism associated with osteoporosis. J Pedod. 1982;7:68-74.

26. Gedik R, Cimen M. Multiple taurodontism: report of case. ASDC J Dent Child. 2000;67:216-7.

27. Sert S, Bayırlı G. Taurodontism in six molars: a case report. J Endod. 2004;30:601-2.

28. Madeira MC, Leite HF, Niccoli Filho WD, Simoes S. Prevalence of taurodontism in premolars. Oral Surg Oral Med Oral Pathol. 1986;61:158-62. 